\title{
Serviceability Assessment Method of Stay Cables with Vibration Control Using First-Passage Probability
}

\author{
Seunghoo Jeong $\mathbb{D}$, Young-Joo Lee $\mathbb{D}$, and Sung-Han Sim \\ School of Urban and Environmental Engineering, Ulsan National Institute of Science and Technology (UNIST), Ulju-gun, \\ Ulsan 44919, Republic of Korea \\ Correspondence should be addressed to Young-Joo Lee; ylee@unist.ac.kr and Sung-Han Sim; ssim@unist.ac.kr
}

Received 11 March 2019; Accepted 18 April 2019; Published 6 May 2019

Academic Editor: Roman Lewandowski

Copyright (C) 2019 Seunghoo Jeong et al. This is an open access article distributed under the Creative Commons Attribution License, which permits unrestricted use, distribution, and reproduction in any medium, provided the original work is properly cited.

\begin{abstract}
As the construction of long-span bridges such as cable-stayed bridges increases worldwide, maintaining bridge serviceability and operability has become an important issue in civil engineering. The stay cable is a principal component of cable-stayed bridges and is generally lightly damped and intrinsically vulnerable to vibration. Excessive vibrations in stay cables can potentially cause long-term fatigue accumulation and serviceability issues. Previous studies have mainly focused on the mitigation of cable vibration within an acceptable operational level, while little attention has been paid to the quantitative assessment of serviceability enhancement provided by vibration control. This study accordingly proposed and evaluated a serviceability assessment method for stay cables equipped with vibration control. Cable serviceability failure was defined according to the range of acceptable cable responses provided in most bridge design codes. The cable serviceability failure probability was then determined by means of the first-passage problem using VanMarcke's approximation. The proposed approach effectively allows the probability of serviceability failure to be calculated depending on the properties of any installed vibration control method. To demonstrate the proposed method, the stay cables of the Second Jindo Bridge in South Korea were evaluated and the analysis results accurately reflected cable behavior during a known wind event and show that the appropriate selection of vibration control method and properties can effectively reduce the probability of serviceability failure.
\end{abstract}

\section{Introduction}

The cable-stayed bridge is currently one of the most commonly used types of long-span bridges worldwide. As the number of constructed cable-stayed bridges increases, maintaining their serviceability and operability is becoming an important issue in civil engineering. Among the different components of a cable-stayed bridge, the stay cable is considered to be a significant member that determines the reliability of the entire bridge [1]. The stay cable is intrinsically vulnerable to large amplitude vibrations stemming from wind, rain, vortex, and deck-cable interactions due to its high flexibility and small mass with low inherent damping [2-4]. Because the cable is incapable of reducing vibration itself, wind-rain induced movement has been reported on cablestayed bridges worldwide after being initially observed in 1986 on the Meiko-West Bridge in Japan [3, 5].

To control cable vibration within acceptable levels, researchers have proposed various methods, including tying multiple cables together, modifying the aerodynamics of cable surfaces, and applying vibration control [6-8]. Tying cables together is a practical approach for reducing vibration by shifting the natural frequency of the cable to avoid resonance, but this method degrades the aesthetics of the bridge [6]. To avoid exposure to external vibration generating forces, the aerodynamics of the cable surface has also been modified [6]. However, this method is only effective within a specific frequency range, and it is difficult to retrofit existing cables [6]. Due to the drawbacks and limitations of the first two approaches, vibration control for stay cables has emerged as an effective and practical alternative $[2,3$, 6-8]. Several studies have proposed passive control using viscous dampers attached transversely to stay cables near the deck anchorages [3, 6, 7]. When well-tuned, such passive viscous dampers can provide supplemental damping to a cable without requiring external power [3]. As a result, this type of damper has been widely applied to many cablestayed bridges worldwide, including the Brotonne Bridge in 
France (1983), the Sunshine Skyway Bridge in Florida (1988), and the Aratsu Bridge in Japan (1989) [6]. The semiactive damper has also received attention as a promising method for mitigating cable vibration, particularly for very long cables [2, $6,7]$. The magnetorheological (MR) damper, one of the more widely used types of semiactive dampers in civil engineering applications, has been applied to the Dongting Lake Bridge in China (2002), the Eiland Bridge in the Netherlands (2005), and the Shandong Binzhou Yellow River Highway Bridge in China (2007) $[2,7,8]$.

Excessive vibration in the stay cables can potentially cause not only long-term fatigue accumulation in the cable and its connectors but also serviceability issues $[6,8]$. Bridge serviceability is the ability of a bridge to be used by the public over a given period of time, while operability is simply the ability of a bridge to continue to function in terms of structural strength $[9,10]$. As bridge users tend to recognize a serviceability problem far earlier than an operability problem due to structural damage caused by vibration [10], a serviceability problem can more readily raise public concern regarding the safety of a cable-stayed bridge. Thus, maintaining appropriate serviceability should be emphasized as one of the primary concerns of bridge maintenance efforts [11-13].

Most modern developed countries have design codes that specify allowable serviceability levels for the cables of cable-supported bridges. For example, in Korea, the Korean Highway Bridge Design Code defines a serviceability failure to have occurred when cable vibration amplitude exceeds $\mathrm{L} / 1600$ at the middle of a stay cable under average wind speed of less than $20 \mathrm{~m} / \mathrm{s}$, where $\mathrm{L}$ is the cable length [14]. The US Department of Transportation classifies the vibration comfort level of bridge users into three levels: 'not allowable' when the cable vibration amplitude exceeds 2.0 D, 'recommended' when the cable vibration amplitude is near 1.0 D, and 'preferred' when the cable vibration amplitude is near $0.5 \mathrm{D}$, where $\mathrm{D}$ is the diameter of the stay cable [15]. In Japan, the serviceability of bridges with stay cables is analyzed on the basis of the criterion of the Japanese Railway Bridge Specifications, which defines allowable deflection as $\mathrm{L} / 2000$ at midspan of the bridge deck, where L is the span length in question [16]. In the Chinese Highway Cablestayed Bridge Design Specification, a serviceability failure is considered to have occurred on a cable-stayed bridge when the deflection at midspan of the bridge deck is over the allowable deflection of the bridge, defined as L/400, where L is the span length in question [1]. Although these allowable serviceability levels are defined in the design codes, little work has been conducted to assess the effects of cable vibration control on cable serviceability.

Accordingly, this study proposed and evaluated a serviceability assessment method for stay cables equipped with vibration control using the first-passage probability. A failure event, in terms of the cable serviceability, was defined as the case in which the subject cable response reached either the upper or lower bound of serviceability provided by the selected design code. The cable serviceability failure probability was then determined by means of the first-passage problem using VanMarcke's approximation. The remainder

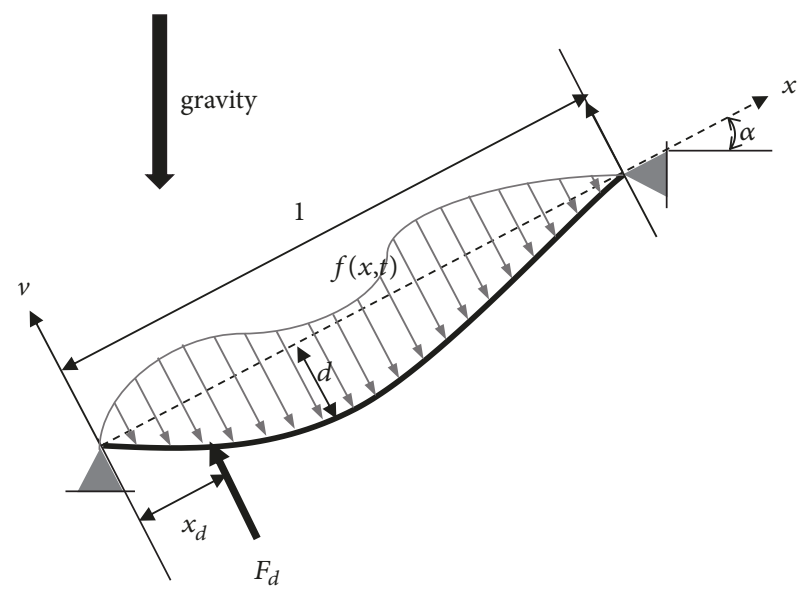

FIGURE 1: Inclined cable with sag and damper.

of this paper is organized as follows. The cable dynamics are first briefly discussed considering cable sag, and aerodynamic wind force is introduced as the external load on the cables. Next, the proposed serviceability assessment method is described and evaluated using an example cablestayed bridge located in Korea. The probability of stay cable serviceability failure when subjected to a given wind force is then evaluated and compared for cases with and without vibration control.

\section{Background}

2.1. Cable Dynamics. This section describes the vibrationcontrolled cable dynamics using an analysis that considers cable characteristics including sag, inclination, static deflection, and flexural rigidity. Consider an inclined cable with a vibration control device, as shown in Figure 1. Based on previous studies $[6,17,18]$, a cable system with a damper can be expressed as a nondimensional partial differential equation of motion for the transverse displacement $v(x, t)$ in the domain $0 \leq x \leq 1$ with boundary conditions $v(0, t)=v(1, t)$ $=0$ for all $t$ as

$$
\begin{aligned}
& \ddot{v}(x, t)+c \dot{v}(x, t)-\frac{1}{\pi^{2}} v^{\prime \prime}(x, t)+\frac{\lambda^{2}}{\pi^{2}}\left[\int_{0}^{1} v(\xi, t) d \xi\right] \\
& =f(x, t)+F_{d}(t) \delta\left(x-x_{d}\right)
\end{aligned}
$$

where $c$ is the nondimensional viscous damping per unit length; $x_{d}$ is the location of the damper; $F_{d}(t)$ is the transverse damping force at $x=x_{d} ; v^{\prime \prime}(x, t)$ is the second order partial derivative of displacement $v$ with respect to $x$; $\ddot{v}(x, t)$ and $\dot{v}(x, t)$ denote partial derivatives with respect to $t ; f(x, t)$ is the distributed load along the cable; $\lambda^{2}$ is the nondimensional sag parameter; and $\delta\left(x-x_{d}\right)$ is the Dirac-delta function. The nondimensional quantities describing the cable are related to their corresponding dimensional quantities, which can be found in [6].

The nondimensional parameter $\lambda^{2}$ considers the effect of cable sag, inclination, and axial stiffness on the cable dynamics $[6,18]$ as follows: 


$$
\begin{aligned}
\lambda^{2} & =\left(\frac{\rho g L \cos \alpha}{T}\right) \frac{E A L}{T L_{e}}=64\left(\frac{\bar{d}}{L}\right)^{2} \frac{E A L}{T L_{e}} \\
L_{e} & =L\left[1+\frac{1}{8}\left(\frac{\rho g L \cos \alpha}{T}\right)^{2}\right], \\
\bar{d} & =L d=\frac{\rho g L^{2} \cos \alpha}{8 T}
\end{aligned}
$$

where $\rho$ is the cable mass per unit length; $\alpha$ is the inclination angle; $L$ is the cable length; $L_{e}$ is the stretched length of the cable; $T$ is the cable tension in the longitudinal direction along the $x$-axis; $d$ is the peak dimensional sag of the cable; $g$ is the gravity; $E$ is the Young's modulus of the cable; and $A$ is a cross-sectional area of the cable. Note that the nondimensional sag parameter $\lambda^{2}$ becomes zero when the effect of cable sag is ignored.

The transverse cable motion $v(x, t)$ can be assumed using a finite series, formed of a combination of generalized coordinates $q_{j}(t)$ and a set of shape functions $\phi_{j}(x)$, that satisfies the boundary conditions $\phi_{j}(0)=\phi_{j}(1)=0$, where $j$ represents the mode number, as follows:

$$
v(x, t)=\sum_{j=1}^{m} q_{j}(t) \phi_{j}(x)
$$

The shape functions of a cable without a damper $\phi_{u n, j}(x)$ can be assumed to be sinusoidal [19], while those of a cable with a damper $\phi_{c o n, j}(x)$ include static deflection as the first shape function and sinusoidal functions for the rest of the modes $[6,19]$. The shape functions for a cable without and with a damper are as follows, respectively:

$$
\begin{aligned}
& \phi_{u n, j}(x)=\sin j \pi x \quad(0 \leq x \leq 1, j=1, \cdots, m) \\
& \phi_{c o n, 1}(x)=\left(\begin{array}{cc}
\frac{x}{x_{d}} & \left(0 \leq x \leq x_{d}\right) \\
\frac{(1-x)}{\left(1-x_{d}\right)} & \left(x_{d} \leq x \leq 1\right)
\end{array}\right. \\
& \phi_{\text {con }, j+1}(x)=\sin j \pi x \quad(0 \leq x \leq 1, j=1, \cdots, m-1)
\end{aligned}
$$

where $m$ is the number of assumed modes.

The equation of motion in (1) can be expressed in matrix form by substituting the cable motion in (3), multiplying by the shape functions, then integrating over the length of the cable. Considering the damper force $F_{d}(t)$ and the additional tension due to cable sag, a cable system with a damper can be described in matrix form as $[6,18]$

$$
\begin{aligned}
\mathrm{M} \ddot{\mathrm{q}}+\mathrm{C} \dot{\mathrm{q}}+\mathrm{Kq} & =\mathrm{f} \\
m_{i j} & =\int_{0}^{1} \phi_{i}(x) \phi_{j}(x) d x, \\
c_{i j} & =c m_{i j}+c_{d} \phi \phi^{T} \\
k_{i j} & =\lambda^{2} k_{i}^{s a g} k_{j}^{\text {sag }}+k_{i j}^{\text {tension }}, \\
f_{i}(t) & =\int_{0}^{1} f(x, t) \phi_{i}(x) d x
\end{aligned}
$$

$$
\begin{aligned}
k_{i}^{\text {sag }} k_{j}^{\text {sag }} & =\frac{1}{\pi^{2}} \int_{0}^{1} \phi_{i}(x) d x \int_{0}^{1} \phi_{j}(x) d x, \\
k_{i j}^{\text {tension }} & =-\frac{1}{\pi^{2}} \int_{0}^{1} \phi^{\prime \prime}{ }_{i}(x) \phi_{j}(x) d x
\end{aligned}
$$

where the mass $\mathrm{M}=\left[m_{i j}\right]$, damping $\mathrm{C}=\left[c_{i j}\right]$, stiffness due to sag and tension $\mathrm{K}=\left[k_{i j}\right]$, generalized coordinates $\mathrm{q}=\left[q_{1}, q_{2} \cdots q_{m}\right]^{T}$, externally applied force $\mathrm{f}=\left[f_{1}, f_{2} \cdots\right.$ $\left.f_{m}\right]^{T}$, and damper load vector $\phi=\left[\phi_{1}\left(x_{d}\right), \phi_{2}\left(x_{d}\right) \cdots\right.$ $\left.\phi_{m}\left(x_{d}\right)\right]^{T}$.

Among the various vibration control schemes available, this study evaluated the passive viscous damper as it has been installed widely on existing cable-stayed bridges [6]. The damper force $F_{d}(t)$ depends on the type of control scheme used when modeling the cable dynamics. When a passive viscous damper is used to control the cable vibration, the nondimensional damper force is $F_{d}(t)=-c_{d} \dot{v}\left(x_{d}, t\right)$ where the $c_{d}$ is nondimensional damping constant and $\dot{v}\left(x_{d}, t\right)$ is the nondimensional velocity at the location of the damper $\dot{v}\left(x_{d}, t\right)=\phi^{T} \dot{\mathrm{q}}[6,19]$. In the case of a cable without a damper, the nondimensional damping constant $c_{d}$ is zero.

2.2. Aerodynamic Wind Force. This section describes the aerodynamic wind force applied to the cable in this study. Let the external force $f(x, t)$ in (1) be assumed to be the aerodynamic wind force $W(t)$, which is uniformly distributed on the cable as

$$
f(x, t)=W(t)
$$

The wind force $W(t)$ on the cable can be derived as a combination of lift and drag forces caused by the oncoming relative wind speed $\left(U_{\text {rel }}\right)$ as [20]

$$
\begin{aligned}
W(t) & =\frac{1}{2} \rho_{\text {air }} D U^{2} C_{y} \\
& =W_{L}\left(\psi_{t}\right) \cos (\psi)+W_{D}\left(\psi_{t}\right) \sin (\psi) \\
W_{L}\left(\psi_{t}\right) & =\frac{1}{2} \rho_{\text {air }} D U_{r e l}^{2} C_{L}\left(\psi_{t}\right), \\
W_{D}\left(\psi_{t}\right) & =\frac{1}{2} \rho_{\text {air }} D U_{r e l}^{2} C_{D}\left(\psi_{t}\right)
\end{aligned}
$$

where $\rho_{\text {air }}$ is the air density; $D$ is the diameter of the cable; $W_{L}$ and $W_{D}$ are the lift and drag forces, respectively; $C_{L}$ and $C_{D}$ are the lift and drag coefficients, respectively; and $\psi_{t}$ is the summation of $\psi, \theta_{0}$, and $\theta$, where $\psi$ is the angle between the direction of the relative wind speed $\left(U_{\text {rel }}\right)$ and the horizontal plane of the cable surface, $\theta_{0}$ is the initial angle of the rainwater rivulet, and $\theta$ is the instantaneous angle of the rivulet.

The oncoming wind is composed of two components of varying magnitude depending on its direction: one perpendicular to the cable axis and the other parallel to the cable axis. As the wind blowing on the cable in the parallel direction has less of an effect on wind-rain induced vibration, this 
study considered only the oncoming wind in the direction perpendicular to the cable axis, denoted by $U$. The oncoming wind causing the cable vibration $(U)$ can then be derived by a function of the inclined angle of the cable $(\alpha)$ and the oncoming wind speed $\left(U_{0}\right)$ for a wind direction angle $(\beta)$ as follows:

$$
\begin{aligned}
U & =U_{0} \sqrt{\cos ^{2} \beta+\sin ^{2} \alpha \sin ^{2} \beta} \\
& =U_{0} \sqrt{\sin ^{2} \alpha+\cos ^{2} \alpha \cos ^{2} \beta} \\
\gamma & =\arcsin \left(\frac{\sin \alpha \sin \beta}{\sqrt{\cos ^{2} \beta+\sin ^{2} \alpha \sin ^{2} \beta}}\right)
\end{aligned}
$$

where $\gamma$ is the angle between the wind direction of $U$ and the horizontal plane of the cable surface. The relative wind speed $U_{\text {rel }}$ with respect to a cable velocity $\dot{y}$ is indicated for an included angle $\psi$ by

$$
\begin{aligned}
U_{r e l} & =\sqrt{(U \cos \gamma)^{2}+(\dot{y}+U \sin \gamma)^{2}} \\
\psi & =\arctan \left(\frac{\dot{y}+U \sin \gamma}{U \cos \gamma}\right)
\end{aligned}
$$

Thus, given the time history data of wind speed $U$ and its associated angles, the wind force $W(t)$ can be obtained. More details regarding the derivation of wind force can be found in [20].

\section{Serviceability Assessment Method Using VanMarcke's First-Passage Probability}

This section describes the proposed serviceability assessment method for stay cables equipped with vibration control measures. Most modern developed countries have design specifications that define the serviceability failure of stay cables [1, 14-16]. For example, the Korean design code states that the maximum allowable deformation of a stay cable must be less than 1/1600 of the cable length at the middle of the cable under the external wind of mean speed less than $20 \mathrm{~m} / \mathrm{s}$ for 10 minutes [14]. The proposed framework was accordingly designed to assess cable serviceability based on such design specifications that define the point of serviceability failure.

The serviceability failure probability can be determined as a first-passage problem using time history data of cable vibration with and without vibration control. Let $P_{f}\left(x_{s} ; \tau\right)$ be the first-passage failure probability of $X(t)$ over a given double-sided threshold $|x|=x_{s}$ during a time interval $t \epsilon(0, \tau)$, where $X(t)$ indicates the cable displacement. Note that the threshold value $x_{s}$ is generally specified by the appropriate design guideline. The approximated form of this probability is [23]

$$
P_{f}\left(x_{s} ; \tau\right) \cong 1-A \exp \left[-\int_{0}^{\tau} \alpha\left(x_{s} ; t\right) d t\right]
$$

where $A$ is the probability of $X(t)$ in the safe domain at $t=$ 0 and $\alpha\left(x_{s} ; t\right)$ is the conditional mean crossing rate at time $t$, given no prior crossings.
Under VanMarcke's approximation [25], the unconditional mean crossing rate of the envelope process $\eta\left(x_{s} ; t\right)$ is used instead of the conditional crossing rate $\alpha\left(x_{s} ; t\right)$ because the conditional crossing rate depends on the bandwidth of the process and duration time in the unsafe region. Additionally, $A$ is replaced with $B$, which indicates the probability that the envelope process is in the safe domain at $t=0$. Using this approximation, the first-passage probability of the cable response can be determined from the following equations:

$$
\begin{aligned}
& P_{f}\left(x_{s} ; \tau\right) \cong 1-B \exp \left[-\int_{0}^{\tau} \eta\left(x_{s} ; t\right) \mathrm{d} t\right] \\
& B=P\left[E(0)<x_{s}\right]=\int_{0}^{x_{s}} f_{E}(e ; 0) \mathrm{d} e \\
& \eta\left(x_{s} ; t\right)=\frac{P\left[E(t) \geq x_{s}\right] v(0 ; t)}{P\left[E(t)<x_{s}\right]}[1 \\
& \left.-\exp \left(\frac{-v_{E}^{+}\left(x_{s} ; t\right)}{P\left[E(t) \geq x_{s}\right] v(0 ; t)}\right)\right]
\end{aligned}
$$

where $E(t)$ is the envelope process of $X(t) ; v\left(x_{s} ; t\right)$ is the unconditional mean crossing rate of $|X(t)|$ over $x_{s}$ under the Poisson approximation; $f_{E}(e ; t)$ is the marginal probability density function of $E(t)$; and $v_{E}{ }^{+}\left(x_{s} ; t\right)$ is the unconditional mean up-crossing rate of $E(t)$.

When $X(t)$ has a stationary and zero-mean Gaussian distribution, $\eta\left(x_{s} ; t\right)$ and $v\left(x_{s} ; t\right)$ are functions of $x_{s}$ only. By employing the envelope defined by [26], $B$ and $\eta\left(x_{s} ; t\right)$ in (13) can be replaced with

$$
\begin{gathered}
B=1-\exp \left(\frac{-r^{2}}{2}\right) \\
\eta\left(x_{s}\right)=\nu\left(x_{s}\right)\left\{\frac{\left[1-\exp \left(-\sqrt{\pi / 2} \delta^{1.2} r\right)\right]}{\left[1-\exp \left(-r^{2} / 2\right)\right]}\right\}
\end{gathered}
$$

where $r=x_{s} / \sigma_{X}$ is the normalized threshold and $\sigma_{X}$ is the standard deviation of $X(t)$. The safety factor characterizing the bandwidth of the process can be defined as $\delta=$ $\left(1-\lambda_{1}^{2} / \lambda_{0} \lambda_{2}\right)^{1 / 2}$, where $\lambda_{m}$ is the spectral moment for $m=0$, 1,2 defined by the frequency domain of the cable response as

$$
\begin{aligned}
& \lambda_{0}=\int_{-\infty}^{\infty} \mathrm{G}_{X X}(\omega) d \omega=\sigma_{X}^{2} \\
& \lambda_{1}=\int_{-\infty}^{\infty}|\omega| \mathrm{G}_{X X}(\omega) d \omega \\
& \lambda_{2}=\int_{-\infty}^{\infty} \omega^{2} \mathrm{G}_{X X}(\omega) d \omega
\end{aligned}
$$

where $G_{X X}(\omega)$ is the power spectral density in the frequency domain of the cable vibration $X(t)$.

Using the VanMarcke's first-passage failure probability, this study determined the probability of cable system serviceability failure, allowing the effect of vibration control on the cable serviceability to be examined. The procedure used in this study for the serviceability assessment of stay cables equipped with vibration control is described in Figure 2. 


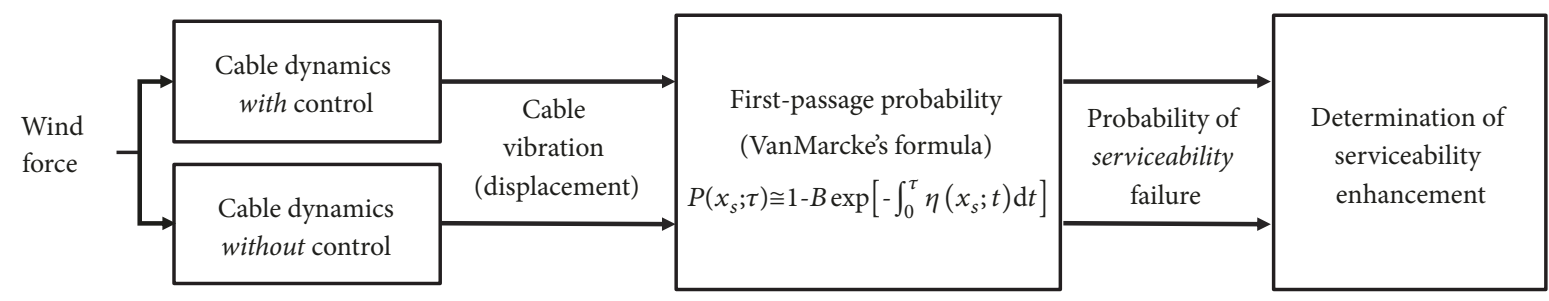

FIGURE 2: Flowchart of stay cable serviceability assessment considering vibration control.

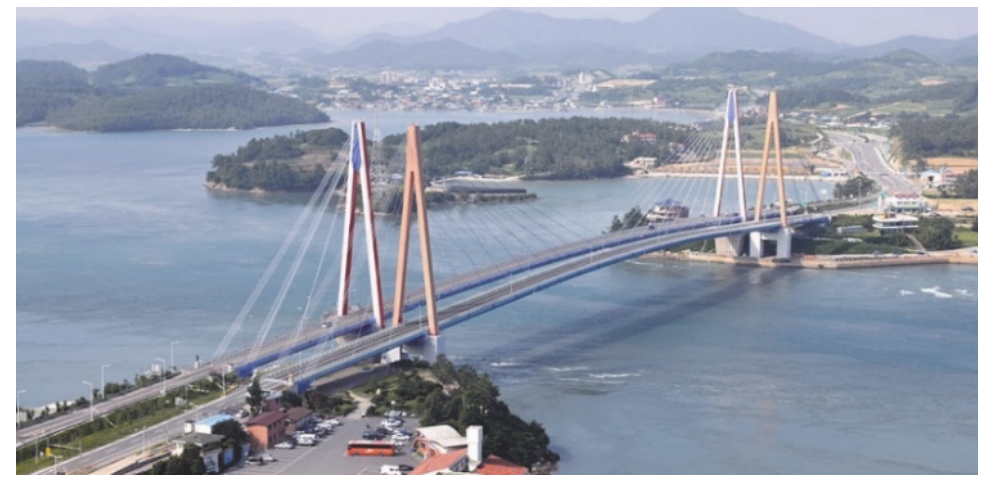

Figure 3: Jindo Bridges (the Second Jindo Bridge is on the left).

\section{Case Study: The Second Jindo Bridge}

4.1. Bridge Description. The Second Jindo Bridge was selected as the case study for the proposed method of assessing cable serviceability considering vibration control. The Second Jindo Bridge, shown in Figure 3, is a 484-m long cablestayed bridge in Korea connecting Jindo Island to the town of Haenam, a southwestern inland region of the Korean Peninsula. In all, 15 different types of cables constitute the 60 total stays that support the bridge, and their properties are summarized in Table 1 [21]. Despite the high-velocity tidal currents at this bridge site, the bridge does not suffer from any scour problem as the pylons were constructed on the land. However, the bridge is only lightly damped and thus vulnerable to both wind-rain and traffic-induced vibrations.

This study investigated Cables C10, C11, and C14 shown in Table 1 to demonstrate the proposed serviceability assessment method. A total of 20 shape functions, including one static deflection term and 19 sine functions, were assumed to construct the combined cable-damper model, which is known to approximately represent the damped cable model [19]. The cable sag due to self-weight was also considered in the cable model in order to provide a more realistic numerical simulation. The passive viscous damper was assumed to be installed at $2 \%$ of the cable length and to have a damping constant $c_{d}=1.5$, providing a $0.5 \%$ additional damping ratio to the cable. Note that the damper is required to produce at least $0.5 \%$ of the critical damping according to the bridge design criteria in Korea [27].

4.2. Dynamic Simulation for Wind-Rain Induced Cable Vibration. Three oncoming wind speed $\left(U_{0}\right)$ cases consisting of different 10-minute mean wind speeds $\left(V_{10}\right)$, shown in
Table 2, were considered to generate the simulated displacement responses. All wind forces were assumed to be uniformly applied to the cables. The time history wind data for the three cases were obtained from the NatHaz On-line Wind Simulator (NOWS) [28] for Exposure Category D, a cut-off frequency of $5 \mathrm{~Hz}$, and time duration of 18,000 s. Note that Exposure Category D is the case for open ocean according to ASCE 7-98. Based on a previous study [20], the numerical analysis in this section simulated wind-rain induced aerodynamic wind force under assumptions of a cable inclination angle $\alpha$ of $30^{\circ}$, wind direction angle $\beta$ of $35^{\circ}$, initial angle $\theta_{0}$ of $20^{\circ}$, and instantaneous angle $\theta$ of $25^{\circ}$.

The simulated responses in Case 1 were compared with the actual measurements acquired during typhoon COMPASU to compensate for possible errors in the dynamic simulations. Then, the generated wind force was modified by matching the standard deviations of the simulated and measured displacements so that the generated results matched the collected data. Let Cable C14 be taken as an example for generating realistic wind forces. When typhoon COMPASU was closest to the Jindo Bridge (Case 1), the dynamic displacement response of Cable C14, which was converted from the measured acceleration, indicated a standard deviation of $0.0036 \mathrm{~m}$ over $60 \mathrm{~s}$ for a wind speed of $12.89 \mathrm{~m} / \mathrm{s}$. The modified wind forces $W(t)$ of Cable $\mathrm{C} 14$ for the three wind cases in Table 2 from 8,000 to $10,000 \mathrm{~s}$ of the $18,000 \mathrm{~s}$ evaluation period are provided in Figure 4 . The wind forces on the other cables were generated using the same procedure.

A time history analysis was conducted to obtain the displacement responses of the cables with and without vibration control. Figure 5 shows the resulting displacement responses of Cable C14 and Table 3 summarizes the standard deviation, maximum displacement, and control efficacy for each wind 
TABLE 1: Cable properties of the Second Jindo Bridge [21].

\begin{tabular}{lccccc}
\hline & Cable & Total length $(\mathrm{m})$ & Diameter $(\mathrm{m})$ & Unit mass (ton/m) & Tension force (tonf) \\
ID & Type & & & 0.0347 & 110.2 \\
C10 & 67 X 109 & 96.515 & 0.095 & 0.0347 & 130.6 \\
C11 & 67 X 109 & 110.940 & 0.095 & 0.0439 & 174.4 \\
C14 & Ø7 X 139 & 157.880 & 0.106 & & \\
\hline
\end{tabular}

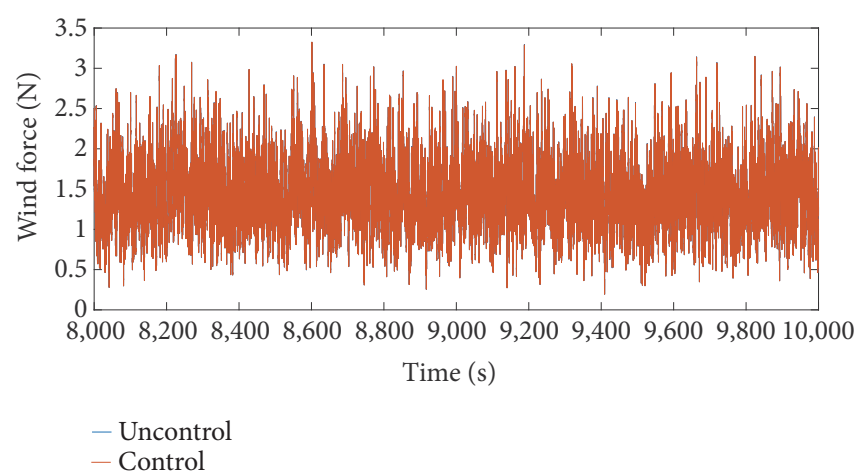

(a) Case $1\left(V_{10}=12.89 \mathrm{~m} / \mathrm{s}\right)$

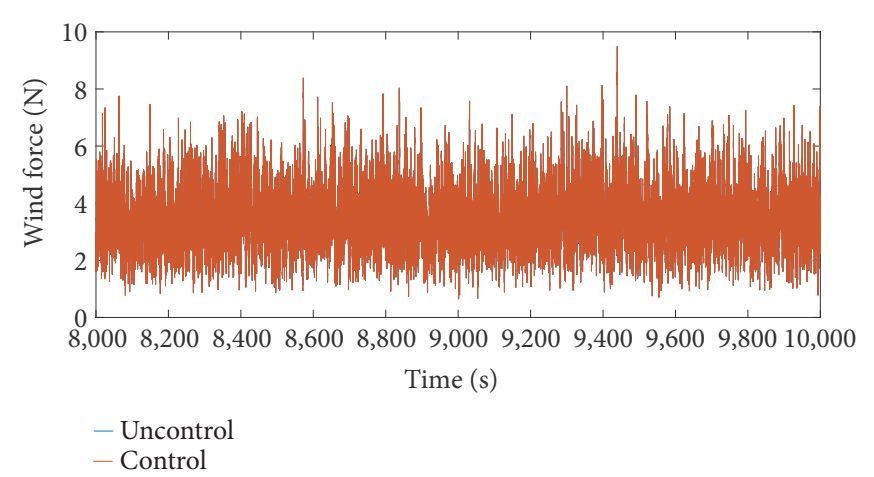

(b) Case $2\left(V_{10}=20 \mathrm{~m} / \mathrm{s}\right)$

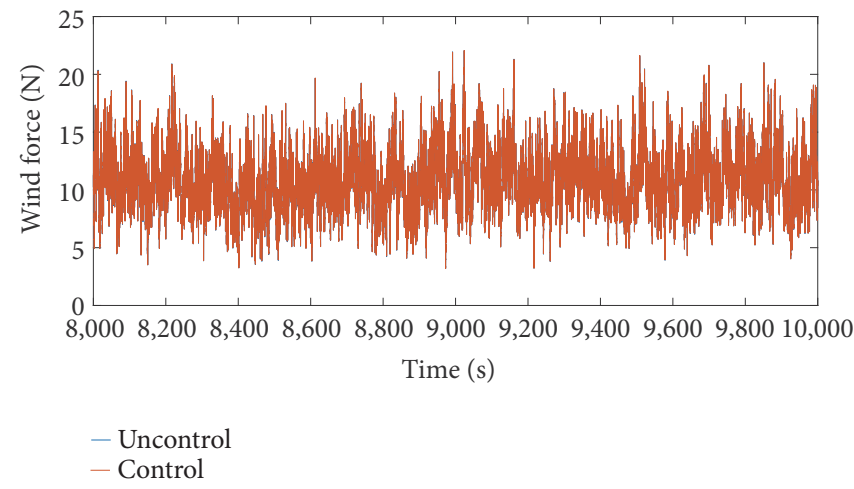

(c) Case $3\left(V_{10}=36 \mathrm{~m} / \mathrm{s}\right)$

Figure 4: Time histories of wind force W(t) for each wind case on Cable C14.

case. Note that the passive viscous damper with $c_{d}=1.5$ was observed to reduce the cable vibration by $40-50 \%$ in most cases, as shown in Table 3.

4.3. Serviceability Assessment. The probability of serviceability failure was evaluated for the three target cables ( $\mathrm{C10}$, C11, and C14) with and without vibration control under the three wind cases as shown in Table 4. Note that the serviceability failure criteria used in this study were adopted from the Korean Highway Bridge Design Code [23], defined as a displacement of over $1 / 1600$ of the cable length at the middle of the cable when the wind speed is less than $20 \mathrm{~m} / \mathrm{s}$ for 10 minutes. Using Cable C14 as an example, the cable can be observed to bear the external wind force without serviceability failure $\left(P_{f}=0\right)$ in Case 1 regardless of the presence of the passive damper. In Case 2, the probability of serviceability failure over one hour was $1.65 \times 10^{-1}$ when uncontrolled but was lowered to $1.15 \times 10^{-12}$ when the passive damper was included. Under the conditions of the most powerful wind measured in Korea (Case 3), the serviceability of the uncontrolled cable exhibits definite failure, while the passively controlled cable exhibits relatively high failure probabilities of $3.59 \times 10^{-1}$ and $5.89 \times 10^{-1}$ for $T=3,600 \mathrm{~s}$ and 7,200 s, respectively.

The probability of serviceability failure can be adjusted by changing the nondimensional damping constant $\left(c_{d}\right)$ as it describes the performance of the passive viscous damper. The probability of serviceability failure for Cable C14 in Case 3 is shown in Figure 6 for damping constants from 0 to 5.0 for $T=3,600 \mathrm{~s}$. As would be expected, increasing the damping constant of the passive damper mitigates the cable vibration and results in a lower probability of serviceability failure. Clearly, the probability of serviceability failure can be effectively controlled to meet design guidelines by adjusting the performance of the installed passive viscous dampers.

\section{Conclusions}

The present study proposed and evaluated a serviceability assessment method for vibration control equipped stay cables 
TABLE 2: Three evaluated oncoming wind speed cases $\left(\mathrm{U}_{0}\right)$.

\begin{tabular}{lcc}
\hline Wind case & $\begin{array}{c}\text { 10-minute mean wind } \\
\text { speed }\left(V_{10}\right)\end{array}$ & Description \\
\hline Case 1 & $12.89 \mathrm{~m} / \mathrm{s}$ & $\begin{array}{c}\text { Mean wind speed when typhoon COMPASU was closest } \\
\text { to the Jindo Bridge (2010.09.01 PM 09:42-09:51) [22] }\end{array}$ \\
\hline Case 2 & $20 \mathrm{~m} / \mathrm{s}$ & $\begin{array}{c}\text { Mean wind speed criterion for serviceability failure as } \\
\text { defined in the Korean Highway Bridge Design Code [23] }\end{array}$ \\
\hline Case 3 & $36 \mathrm{~m} / \mathrm{s}$ & $\begin{array}{c}\text { Maximum mean wind speed when typhoon RUSA } \\
\text { (2002.08.31, the most powerful typhoon in Korea) passed } \\
\text { through the Korean peninsula [24] }\end{array}$ \\
\hline
\end{tabular}

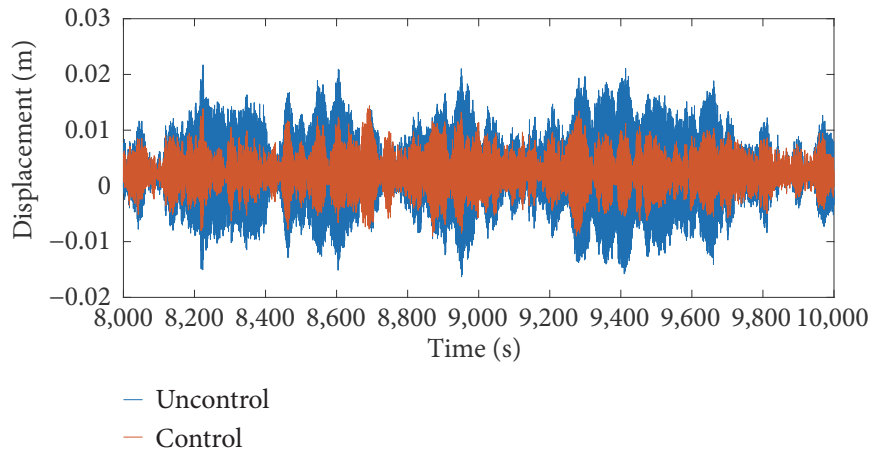

(a) Case $1\left(V_{10}=12.89 \mathrm{~m} / \mathrm{s}\right)$

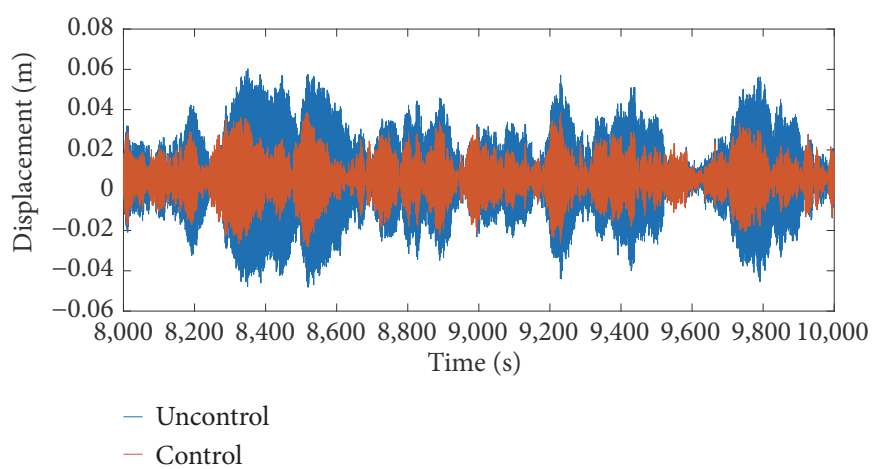

(b) Case $2\left(V_{10}=20 \mathrm{~m} / \mathrm{s}\right)$

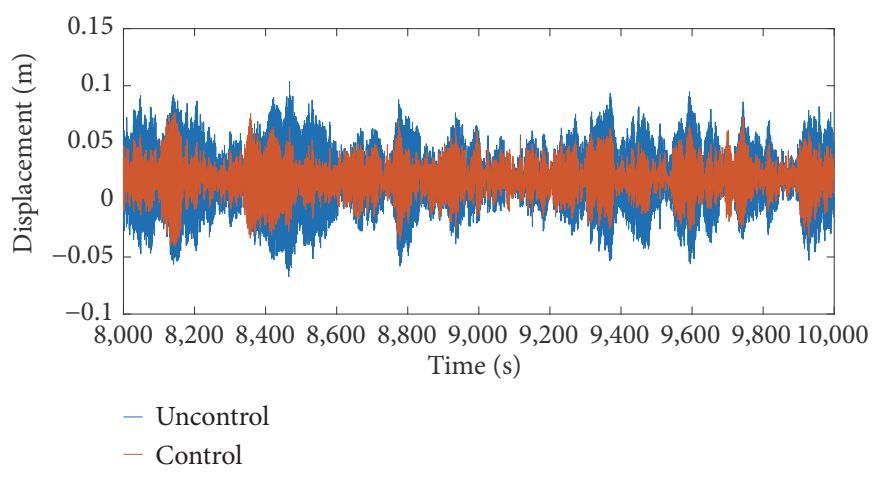

(c) Case $3\left(V_{10}=36 \mathrm{~m} / \mathrm{s}\right)$

Figure 5: Time histories of cable vibration for $c_{d}=1.5$ on Cable C14.

when subjected to external wind forces causing wind-rain induced vibration. The cable serviceability failure event used in this method was defined according to when the cable response reached either the upper or lower bound given in the relevant bridge design code. Treating the cable behavior as a first-passage problem, the probability of serviceability failure was assumed to be the probability of the cable response first moving outside the defined limits during a prescribed 
TABLE 3: Numerical results of cable vibration (displacement) with/without vibration control on Cable C14.

\begin{tabular}{|c|c|c|c|c|c|c|}
\hline \multirow[b]{2}{*}{ Wind cases } & \multicolumn{3}{|c|}{ Standard deviation } & \multicolumn{3}{|c|}{ Maximum displacement (m) } \\
\hline & Un-controlled & $\begin{array}{c}\text { Passive control } \\
\quad\left(c_{d}=1.5\right)\end{array}$ & $\begin{array}{c}\text { Control } \\
\text { efficacy }(\%)\end{array}$ & Un-controlled & $\begin{array}{l}\text { Passive control } \\
\qquad\left(c_{d}=1.5\right)\end{array}$ & $\begin{array}{c}\text { Control efficacy } \\
(\%)\end{array}$ \\
\hline $\begin{array}{l}\text { Case } 1 \\
\left(V_{10}=12.89 \mathrm{~m} / \mathrm{s}\right)\end{array}$ & $6.45 \times 10^{-3}$ & $3.32 \times 10^{-3}$ & 48.53 & $2.71 \times 10^{-2}$ & $1.38 \times 10^{-2}$ & 49.01 \\
\hline $\begin{array}{l}\text { Case } 2 \\
\left(V_{10}=20 \mathrm{~m} / \mathrm{s}\right)\end{array}$ & $1.72 \times 10^{-2}$ & $9.21 \times 10^{-3}$ & 46.45 & $7.10 \times 10^{-2}$ & $3.82 \times 10^{-2}$ & 46.20 \\
\hline $\begin{array}{l}\text { Case } 3 \\
\left(V_{10}=36 \mathrm{~m} / \mathrm{s}\right)\end{array}$ & $2.82 \times 10^{-2}$ & $1.64 \times 10^{-2}$ & 41.84 & $1.17 \times 10^{-1}$ & $8.41 \times 10^{-2}$ & 28.12 \\
\hline
\end{tabular}

TABLE 4: Calculated probability of serviceability failure $(P f)$.

\begin{tabular}{|c|c|c|c|c|c|}
\hline \multirow{2}{*}{\multicolumn{3}{|c|}{ Case parameters }} & \multicolumn{3}{|c|}{ Probability of serviceability failure $\left(P_{f}\right)$} \\
\hline & & & Cable C10 & Cable C11 & Cable C14 \\
\hline \multirow{4}{*}{$\begin{array}{l}\text { Case } 1 \\
\left(V_{10}=12.89 \mathrm{~m} / \mathrm{s}\right)\end{array}$} & \multirow{2}{*}{ Uncontrolled } & $T=3,600 \mathrm{~s}$ & $8.92 \times 10^{-6}$ & 0 & 0 \\
\hline & & $T=7,200 \mathrm{~s}$ & $1.78 \times 10^{-5}$ & 0 & 0 \\
\hline & \multirow{2}{*}{$\begin{array}{l}\text { Passive control } \\
\qquad\left(c_{d}=1.5\right)\end{array}$} & $T=3,600 \mathrm{~s}$ & 0 & 0 & 0 \\
\hline & & $T=7,200 \mathrm{~s}$ & 0 & 0 & 0 \\
\hline \multirow{4}{*}{$\begin{array}{l}\text { Case } 2 \\
\left(V_{10}=20 \mathrm{~m} / \mathrm{s}\right)\end{array}$} & \multirow{2}{*}{ Uncontrolled } & $T=3,600 \mathrm{~s}$ & 1 & $9.23 \times 10^{-1}$ & $1.65 \times 10^{-1}$ \\
\hline & & $T=7,200 \mathrm{~s}$ & 1 & $9.94 \times 10^{-1}$ & $3.04 \times 10^{-1}$ \\
\hline & \multirow{2}{*}{$\begin{array}{l}\text { Passive control } \\
\qquad\left(c_{d}=1.5\right)\end{array}$} & $T=3,600 \mathrm{~s}$ & $4.91 \times 10^{-1}$ & $6.20 \times 10^{-7}$ & $1.15 \times 10^{-12}$ \\
\hline & & $T=7,200 \mathrm{~s}$ & $7.40 \times 10^{-1}$ & $1.24 \times 10^{-6}$ & $2.30 \times 10^{-12}$ \\
\hline \multirow{4}{*}{$\begin{array}{l}\text { Case } 3 \\
\left(V_{10}=36 \mathrm{~m} / \mathrm{s}\right)\end{array}$} & \multirow{2}{*}{ Uncontrolled } & $T=3,600 \mathrm{~s}$ & 1 & 1 & 1 \\
\hline & & $T=7,200 \mathrm{~s}$ & 1 & 1 & 1 \\
\hline & \multirow{2}{*}{$\begin{array}{l}\text { Passive control } \\
\qquad\left(c_{d}=1.5\right)\end{array}$} & $T=3,600 \mathrm{~s}$ & 1 & 1 & $3.59 \times 10^{-1}$ \\
\hline & & $T=7,200 \mathrm{~s}$ & 1 & 1 & $5.89 \times 10^{-1}$ \\
\hline
\end{tabular}

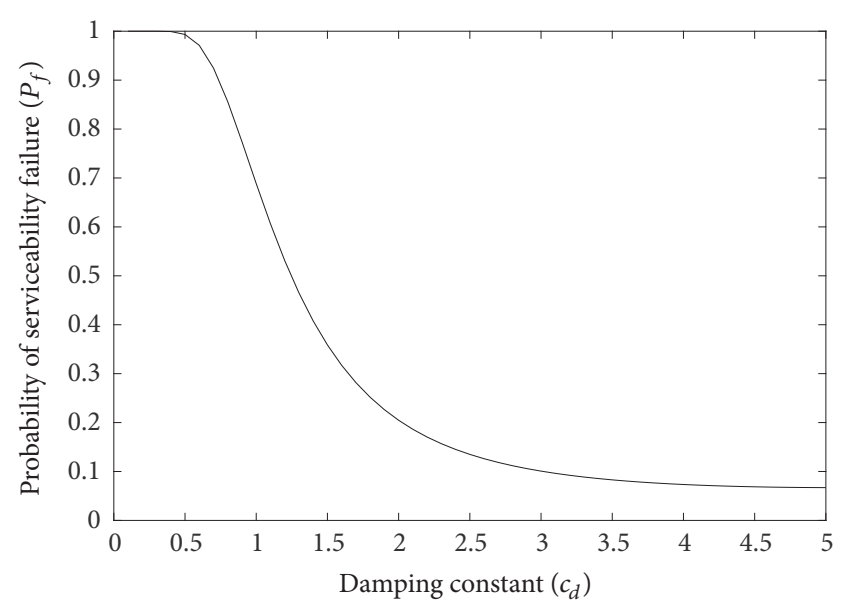

Figure 6: Probability of serviceability failure of Cable C14 versus nondimensional damping constants $\left(c_{d}\right)$ in Case 3.

time interval. The cable dynamics were simulated considering not only cable sag but also inclination angle, flexural rigidity, and static deflection to construct a realistic cable model, and a passive viscous damper was selected as the damping device. By using a VanMarcke's approximation, this study then assessed the probability of serviceability failure of the cables used in the Second Jindo Bridge in Korea depending on the presence of vibration control. According to the Korean Highway Bridge Design Code, the cable vibration serviceability failure threshold was set to $1 / 1600$ of the cable length [14]. The proposed method showed a clear correlation between the behavior calculated using the proposed method and data collected under the same wind speed event. The results demonstrate that the proposed serviceability assessment method can be used to provide a guideline to determine the possibility of using of a cable-stayed bridge and the appropriate damping systems given the wind environment and can serve as a criterion to establish the appropriate time interval for assessing the probability of serviceability failure.

Although this study provides a new perspective on the serviceability assessment method of stay cables equipped with vibration control, several limitations remain to be addressed. First, in this study, the external force was assumed to be only due to wind-rain induced vibration; however, in reality, the applied external forces include various additional factors, such as vortexes and traffic. If all such external forces can be accurately modeled, the outcome of this method will more closely reflect reality. Second, this study evaluated the effects of a passive viscous damper as the control device to identify the enhancement of cable serviceability. The assessment of other control devices, such as the magnetorheological (MR) damper, remains necessary to support the results of this study. 


\section{Data Availability}

The data used to support the findings of this study are included within the article.

\section{Conflicts of Interest}

The authors declare that they have no conflicts of interest.

\section{Acknowledgments}

The research described in this paper was financially supported by a grant [16CTAP-C097436-02] from the Infrastructure and Transportation Technology Promotion Research Program funded by the Ministry of Land, Infrastructure, and Transport of the Korean Government.

\section{References}

[1] J. Cheng and R.-C. Xiao, "Serviceability reliability analysis of cable-stayed bridges," Structural Engineering and Mechanics, vol. 20, no. 6, pp. 609-630, 2005.

[2] Y. F. Duan, Y. Q. Ni, and J. M. Ko, "Cable vibration control using magnetorheological dampers," Journal of Intelligent Material Systems and Structures, vol. 17, no. 4, pp. 321-325, 2006.

[3] M. Maślanka, B. Sapinski, and J. Snamina, "Experimental study of vibration control of a cable with an attached MR damper," Journal of Theoretical and Applied Mechanics, vol. 45, no. 4, pp. 893-917, 2007.

[4] Y. Fujino, K. Kimura, and H. Tanaka, Wind Resistant Design of Bridges in Japan, Springer, Tokyo, Japan, 2012.

[5] Z. Q. Chen, X. Y. Wang, and J. M. Ko, "MR damping system for mitigating wind-rain induced vibration on Dongting Lake Cable-Stayed Bridge," Wind \& Structures, vol. 7, no. 5, pp. 293304, 2004.

[6] E. A. Johnson, R. E. Christenson, and B. F. Spencer Jr., "Semiactive damping of cables with sag," Computer-Aided Civil and Infrastructure Engineering, vol. 18, no. 2, pp. 132-146, 2003.

[7] W. J. Wu and C. S. Cai, "Experimental study of magnetorheological dampers and application to cable vibration control," Journal of Vibration and Control, vol. 12, no. 1, pp. 67-82, 2006.

[8] H. Li, M. Liu, J. Li, X. Guan, and J. Ou, "Vibration control of stay cables of the shandong binzhou yellow river highway bridge using magnetorheological fluid dampers," Journal of Bridge Engineering, vol. 12, no. 4, pp. 401-409, 2007.

[9] E. Jenelius, T. Petersen, and L.-G. Mattsson, "Importance and exposure in road network vulnerability analysis," Transportation Research Part A: Policy and Practice, vol. 40, no. 7, pp. 537560, 2006.

[10] S. Živanović, A. Pavic, and P. Reynolds, "Vibration serviceability of footbridges under human-induced excitation: a literature review," Journal of Sound and Vibration, vol. 279, no. 1-2, pp. 174, 2005.

[11] A. C. Estes and D. M. Frangopol, "Bridge lifetime system reliability under multiple limit states," Journal of Bridge Engineering, vol. 6, no. 6, pp. 523-528, 2001.

[12] C. Minervino, B. Sivakumar, F. Moses, D. Mertz, and W. Edberg, "New AASHTO guide manual for load and resistance factor rating of highway bridges," Journal of Bridge Engineering, vol. 9, no. 1, pp. 43-54, 2004.
[13] Y. Jeong, W. Kim, I. Lee, and J. Lee, "Bridge inspection practices and bridge management programs in China, Japan, Korea, and U.S., Journal of Structural Integrity and Maintenance, vol. 3, no. 2, pp. 126-135, 2018.

[14] Ministry of Land, Infrastructure and Transport, Korean Highway Bridge Design Code, Korea road and Transportation Association, 2016.

[15] S. Kumarasena, N. P. Jones, P. Irwin, and P. Taylor, WindInduced Vibration of Stay Cables, Federal Highway Administration, Washington, DC, USA, 2007.

[16] F. Samim and S. Nakamura, "Static and Seismic Characteristics of Cable-Stayed Bridges with New Stay Systems," IABSE Symposium Report, vol. 105, no. 8, pp. 1-8, 2015.

[17] H. M. Irvine, Cable Structures, MIT Press, Cambridge, UK, 1981.

[18] B. M. Pacheco, Y. Fujino, and A. Sulekh, "Estimation curve for modal damping in stay cables with viscous damper," Journal of Structural Engineering (United States), vol. 119, no. 6, pp. 19611979, 1993.

[19] E. A. Johnson, G. A. Baker, B. F. Spencer Jr., and Y. Fujino, "Semiactive damping of stay cables," Journal of Engineering Mechanics, vol. 133, no. 1, pp. 1-11, 2007.

[20] M. Gu, X. Q. Du, and S. Y. Li, "Experimental and theoretical simulations on wind-rain-induced vibration of 3-D rigid stay cables," Journal of Sound and Vibration, vol. 320, no. 1-2, pp. 184200, 2009.

[21] Y. S. Park, S. M. Choi, W. Y. Yang, H. J. Hong, and W. H. Kim, "A study on tension for cables of a cable-stayed bridge damper is attached," Journal of Korean Society of Steel Construction, vol. 20, no. 5, pp. 609-616, 2008.

[22] Korea Meteorological Administration, 2009, http://www.kma .go.kr.

[23] L. D. Lutes and S. Sarkani, Random Vibrations: Analysis of Structural And Mechanical Systems, Butterworth-Heinemann, Oxford, UK, 2004.

[24] Korea Meteorological Administration, Typhoon White Book, 2006.

[25] E. H. Vanmarcke, "On the distribution of the first-passage time for normal stationary random processes," Journal of Applied Mechanics, vol. 42, no. 1, pp. 215-220, 1975.

[26] H. Cramér and M. R. Leadbetter, Stationary and Related Stochastic Processes: Sample Function Properties and Their Applications, Courier Corporation, North Chelmsford, Mass, USA, 2013.

[27] I. H. Jung, C. M. Park, M. G. Yoon et al., "Special articles: design criteria of incheon bridge project," Journal of Korean Society of Steel Construction, vol. 17, no. 3, pp. 8-16, 2005.

[28] D. Kwon and A. Kareem, "NatHaz on-line wind simulator (NOWS): simulation of Gaussian multivariate wind fields," in NatHaz Modeling Laboratory Report, University of Notre Dame, 2006, http://windsim.ce.nd.edu/. 


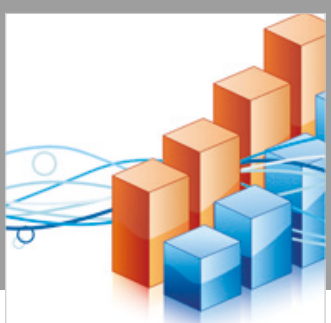

Advances in

Operations Research

\section{-n-m}
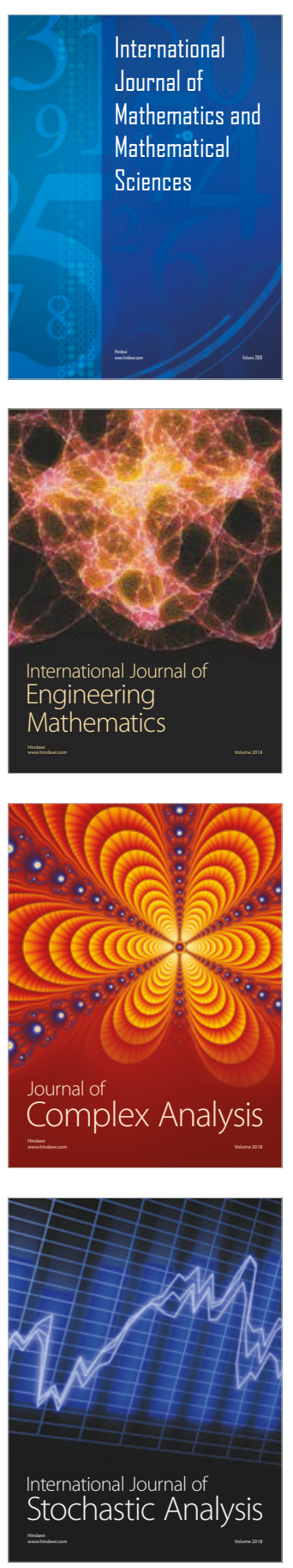
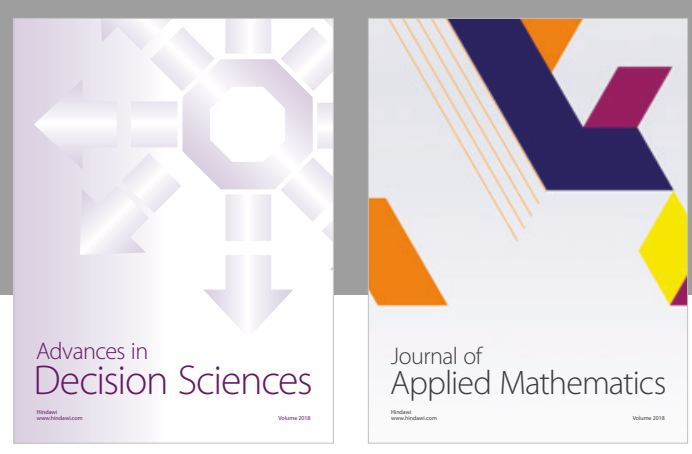

Journal of

Applied Mathematics
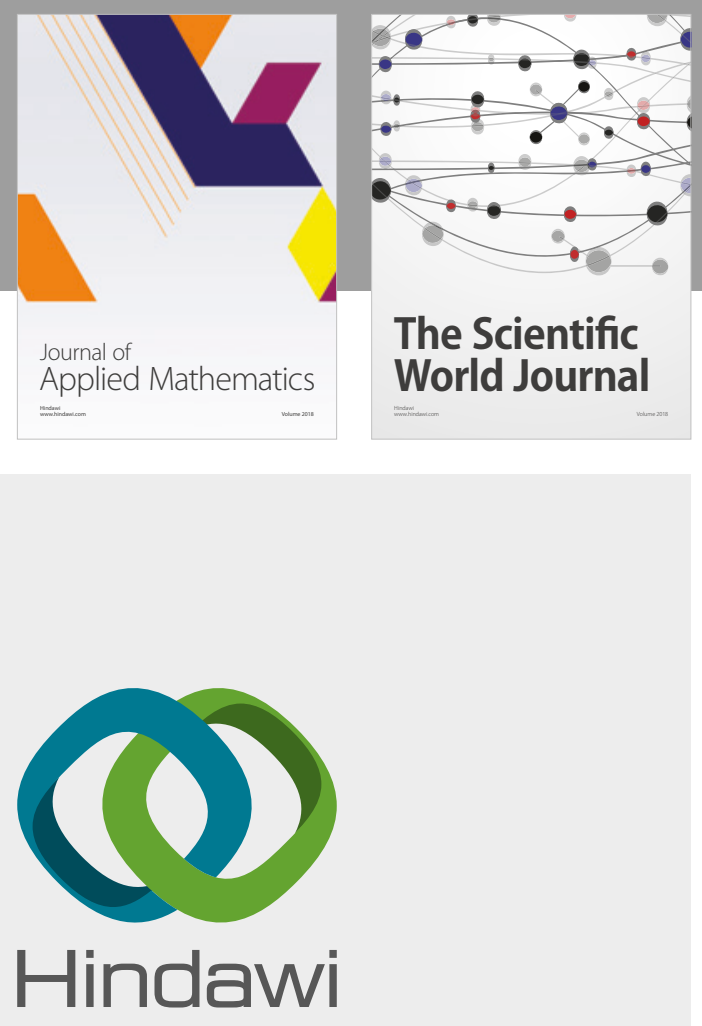

Submit your manuscripts at

www.hindawi.com

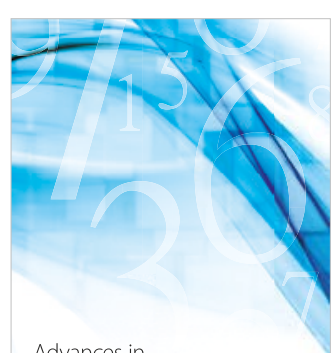

Advances in
Numerical Analysis
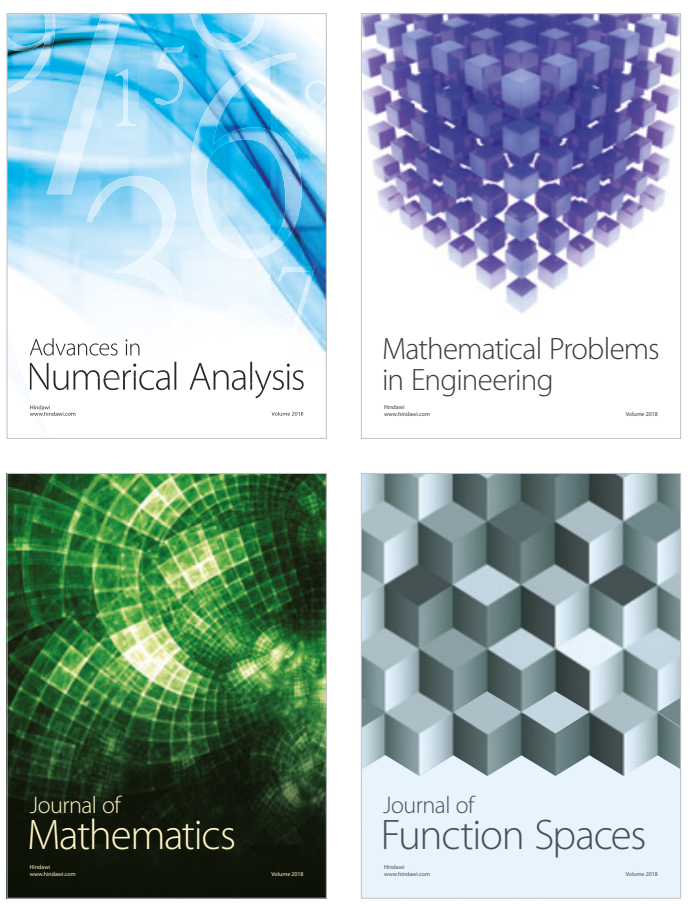

Mathematical Problems in Engineering

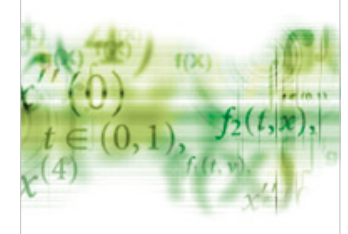

International Journal of

Differential Equations

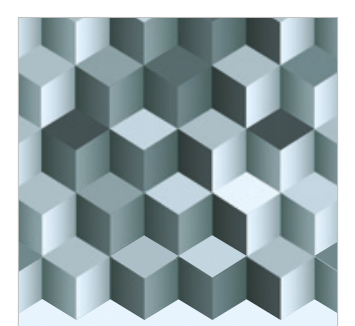

Journal of

Function Spaces

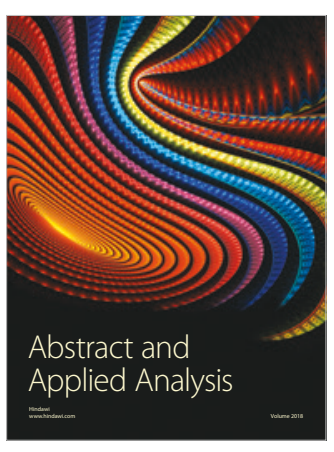

The Scientific

World Journal

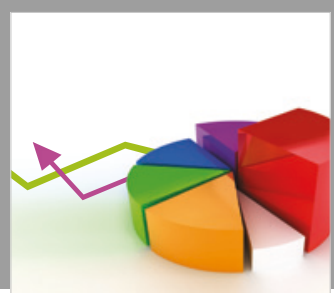

Journal of

Probability and Statistics
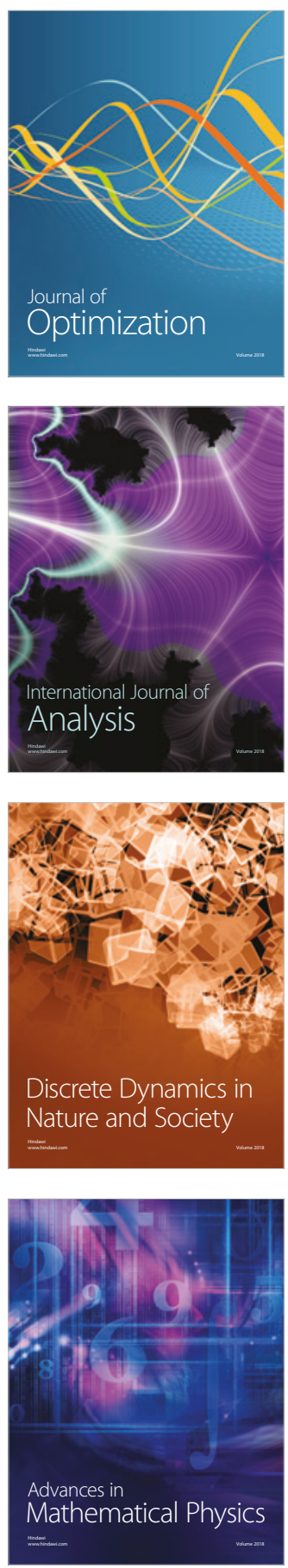